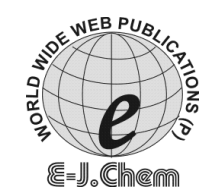

http://www.e-journals.net

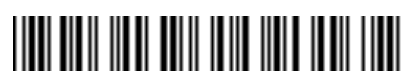

ISSN: 0973-4945; CODEN ECJHAO

E-Journal of Chemistry

Vol. 4, No.3, pp. 363-371, July 2007

\title{
Conformational Analysis (Semi Empirical PM3) and Electronic Properties of Functionalized Oligo(hexylpyrroles)
}

\author{
O. A ODUNOLA* and B. SEMIRE \\ Department of Pure and Applied Chemistry, \\ Ladoke Akintola University of Technology, Ogbomoso, Nigeria. \\ odunola@yahoo.com; semireban@yahoo.com
}

Received 12 December 2006; Accepted 10 January 2007

\begin{abstract}
A semi empirical analysis of functionalized 3-hexylpyrroles

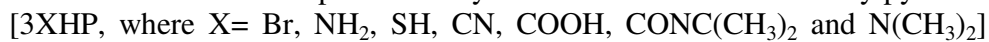
having functional group attached to the hexyl substituent up to four monomeric units in head-tail-head-tail regioselectivity was carried out. The energy band gap obtained at PM3 level showed that oligomers with 3BHP present lowest energy band gap. The energy band gap changed with the functional group attached to hexyl substitutents, which affect the molecular properties related to the electronic conductivity.
\end{abstract}

Keywords: Functionalized hexylpyrroles, Energy band gap, Semi empirical (PM3).

\section{Introduction}

Polypyrrole is one of the most frequently used conducting polymers as gas sensors, wires, mircoactuators, antielectrostatic coating, solid electrolytic capacitors, polymeric batteries, electronic devices and functional membranes ${ }^{1-7}$.This is no doubt due to long-term stability of its conductivity and the possibility of forming homopolymers or composites with optimal properties $^{8,9}$.

Theoretically, a number of attempts have been made employing semi empirical quantum mechanical calculations for geometries and rotational barriers of oligopyrroles ${ }^{10-12}$, effective valence Hamiltonian approximation on bond structure ${ }^{13}$ and small basis ab initio calculations on small oligomers of pyrroles and their derivatives ${ }^{14,15}$. Thermodynamical stabilities of $\alpha-\alpha, \alpha-\beta$ and $\beta-\beta$ dimmers of pyrrole using Hartree Fock (HF), Density Functional Theory (DFT) and Moller-Plesset (MP2) have been studied ${ }^{16}$. In this work, the 
functionalized hexylpyrrole (3XHP) oligomers of $n$ monomeric units ( $n=1,2,3$ and 4) were studied in Head-Tail-Head-Tail using semi empirical method at PM3 level of calculations. Energy band gaps are discussed as a function of the number of monomeric units and functionalized hexyl substitutents.

\section{Computational Details}

Conformational analysis was carried out on the molecules sketched in Figure 1. Initial geometries were optimized at Molecular Mechanics (MMFF94) ${ }^{17}$ and further reoptimized using semi empirical method at PM3 level ${ }^{18}$. The vibrational frequency calculations were carried out to characterize the stationary points and symmetry constraints were not imposed. The functionalized hexylpyrroles (3XHP) considered are 3-Bromohexylpyrrole (3BHP), 3-(2(4,4-dimethylthyloxazolin-2-yl)heptylpyrrole (3DTHP), 3-Heptanic acid pyrroles (3HAP), 3-Thiohexylpyrrole (3THP), 3-Cyanohexylpyrrole (3CHP), 3-Aminopyrrole (3AHP) and 3-(N,N-dimethyl)-aminohexylpyrrole (3DAHP). All calculations ${ }^{19}$ were performed using Spartan Essential 2.0.1.<smiles>[X][14CH2]c1c[nH]c(C)c1</smiles>

(a)

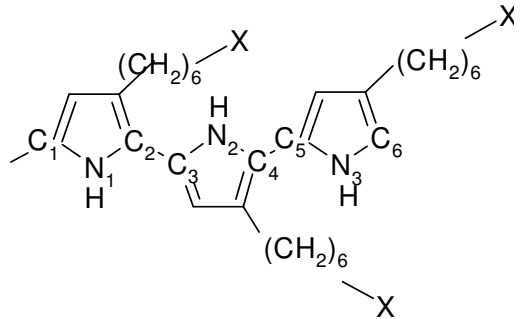

(c)

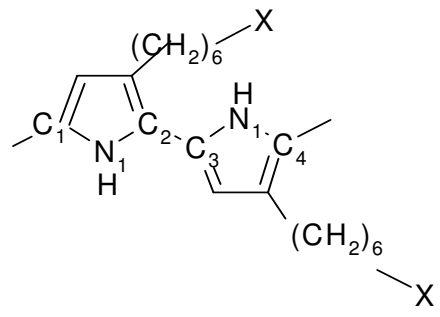<smiles></smiles>

(d)

Figure 1. Structure of functionalized poly(3- hexylpyrroles) oligomers of $\mathrm{n}$ monomeric units ( $\mathrm{n}=1,2,3$ and 4). Where, $\mathrm{X}=\mathrm{Br}, \mathrm{NH}_{2}, \mathrm{SH}, \mathrm{CN}, \mathrm{COOH}, \mathrm{CONC}\left(\mathrm{CH}_{3}\right)_{2}$ and $\mathrm{N}\left(\mathrm{CH}_{3}\right)_{2}$

\section{Results and Discussion}

\section{Geometries}

The bond lengths and bond angles are listed in Tables 1 and 2. The interrings $\mathrm{C}-\mathrm{C}$ bond lengths are quite similar $\left(1.440 \mathrm{~A}^{\circ}\right.$ to $\left.1.442 \mathrm{~A}^{\circ}\right)$ for all the functionalized hexylpyrroles (3XHP) but slightly shorten than that of functionalized hexylthiophenes (3XHT) analogues calculated at the same PM3 level $^{20}$. The interring distances calculated for 3XHP dimers are slightly shorter than that of unsubstituted pyrrole dimers calculated at Hartree Fock (HF) using different basis sets ${ }^{16}$. The largest changes that occur to the interring bond are that of 3DTHP, which become longer due to the bulky dimethyloxazoline-2-yl group. There is slight lengthening of $\mathrm{N}_{1}-\mathrm{C}_{2}$ as $3 \mathrm{XHP}$ becomes larger, which indicates an increment in delocalisation of $\pi$-electrons; hence increase in conductivity character ${ }^{21}$. All the structures are largely twisted at equilibrium geometries. 
Table 1. Selected bond lengths $(\AA)$ and bond angles $\left({ }^{0} \mathrm{C}\right)$ for optimized structure of Functionalized poly(3-hexylpyrroles) oligomers at PM3.

\begin{tabular}{|c|c|c|c|c|c|c|c|}
\hline $\begin{array}{l}\text { Number of } \\
\text { units (n) } \\
\mathrm{n}=1\end{array}$ & \multicolumn{7}{|c|}{ 3- Hexylpyrrole Derivatives } \\
\hline Bond length & $3 \mathrm{BHP}$ & $3 \mathrm{AHP}$ & 3 THP & $3 \mathrm{CHP}$ & 3НAHP & 3DTHP & 3DAHP \\
\hline $\mathrm{N}_{1}-\mathrm{C}_{1}$ & 1.396 & 1.396 & 1.397 & 1.396 & 1.397 & 1.395 & 1.396 \\
\hline $\mathrm{N}_{1}-\mathrm{C}_{2}$ & 1.397 & 1.397 & 1.396 & 1.397 & 1.396 & 1.396 & 1.397 \\
\hline Bond angle & & & & & & & \\
\hline $\mathrm{C}_{1} \mathrm{~N}_{1} \mathrm{C}_{2}$ & 109.82 & 109.82 & 109.83 & 109.82 & 109.83 & 109.85 & 109.82 \\
\hline \multicolumn{8}{|l|}{$\mathrm{n}=2$} \\
\hline \multicolumn{8}{|l|}{ Bond length } \\
\hline $\mathrm{N}_{1}-\mathrm{C}_{1}$ & 1.394 & 1.397 & 1.393 & 1.394 & 1.395 & 1.397 & 1.394 \\
\hline $\mathrm{N}_{1}-\mathrm{C}_{2}$ & 1.401 & 1.401 & 1.401 & 1.403 & 1.404 & 1.402 & 1.402 \\
\hline $\mathrm{C}_{2}-\mathrm{C}_{3}$ & 1.440 & 1.440 & 1.440 & 1.443 & 1.444 & 1.440 & 1.442 \\
\hline $\mathrm{N}_{2}-\mathrm{C}_{3}$ & 1.403 & 1.402 & 1.403 & 1.403 & 1.403 & 1.402 & 1.403 \\
\hline $\mathrm{N}_{2}-\mathrm{C}_{4}$ & 1.393 & 1.391 & 1.393 & 1.393 & 1.393 & 1.391 & 1.393 \\
\hline Bond angle & & & & & & & \\
\hline $\mathrm{C}_{1} \mathrm{~N}_{1} \mathrm{C}_{2}$ & 109.72 & 109.64 & 109.81 & 109.40 & 109.44 & 109.64 & 109.45 \\
\hline $\mathrm{C}_{3} \mathrm{~N}_{2} \mathrm{C}_{4}$ & 109.96 & 109.19 & 109.93 & 109.58 & 109.49 & 109.19 & 109.61 \\
\hline \multicolumn{8}{|l|}{$\mathrm{n}=3$} \\
\hline \multicolumn{8}{|l|}{ Bond length } \\
\hline $\mathrm{N}_{1}-\mathrm{C}_{1}$ & 1.393 & 1.393 & 1.393 & 1.393 & 1.393 & 1.392 & 1.393 \\
\hline $\mathrm{N}_{1}-\mathrm{C}_{2}$ & 1.403 & 1.404 & 1.403 & 1.403 & 1.403 & 1.403 & 1.403 \\
\hline $\mathrm{C}_{2}-\mathrm{C}_{3}$ & 1.440 & 1.440 & 1.440 & 1.440 & 1.440 & 1.442 & 1.440 \\
\hline $\mathrm{N}_{2}-\mathrm{C}_{3}$ & 1.399 & 1.398 & 1.399 & 1.398 & 1.399 & 1.399 & 1.399 \\
\hline $\mathrm{N}_{2}-\mathrm{C}_{4}$ & 1.400 & 1.400 & 1.400 & 1.401 & 1.401 & 1.402 & 1.400 \\
\hline $\mathrm{C}_{4} \mathrm{C}_{5}$ & 1.440 & 1.440 & 1.440 & 1.440 & 1.440 & 1.440 & 1.440 \\
\hline $\mathrm{N}_{3}-\mathrm{C}_{5}$ & 1.402 & 1.402 & 1.402 & 1.402 & 1.402 & 1.402 & 1.402 \\
\hline $\mathrm{N}_{3}-\mathrm{C}_{6}$ & 1.393 & 1.393 & 1.393 & 1.393 & 1.393 & 1.393 & 1.393 \\
\hline \multicolumn{8}{|l|}{ Bond angle } \\
\hline $\mathrm{C}_{1} \mathrm{~N}_{1} \mathrm{C}_{2}$ & 109.84 & 109.85 & 109.84 & 109.85 & 109.85 & 109.64 & 109.84 \\
\hline $\mathrm{C}_{3} \mathrm{~N}_{2} \mathrm{C}_{4}$ & 109.65 & 109.66 & 109.65 & 109.69 & 109.64 & 109.36 & 109.65 \\
\hline $\mathrm{C}_{5} \mathrm{~N}_{2} \mathrm{C}_{6}$ & 109.58 & 109.57 & 109.58 & 109.59 & 109.58 & 109.56 & 109.58 \\
\hline
\end{tabular}

\section{Homo-lumo energy band gap}

Spectroscopic data for organic $\pi$ - systems are usually determined either in solution or in solid state (crystal or thin film). However, since our calculations are for isolated molecules in the gas phase, we have attempted to correlate functional groups on the hexyl substituent to the energy band gap of the pyrroles. Table 4 summarizes the energy band gap of intrinsic functionalized hexylpyrroles (3XHP) monomers, dimers, trimers and tetramers at PM3. It is interesting to note the decrease in energy band gap as the oligomer chain becomes larger. The infinity energy band gaps for 3XHP were predicted in Figure 2. The quality of the correlation used is exemplified for the HT-HT derivatives as shown in Figure 1. Analysing the values HOMO-LUMO differences (Table 4) show that the energy band gaps obtained for $3 \mathrm{XHP}$ could be arranged in decreasing order as $3 \mathrm{BHP}>3 \mathrm{DAHP}>3 \mathrm{THP}>3 \mathrm{AHP}>3 \mathrm{HAHP}>3 \mathrm{CHP}>3 \mathrm{DTHP}$. 
Table 2. Selected bond lengths $(\AA)$ and bond angles $\left({ }^{0} \mathrm{C}\right)$ for optimized structure of functionalized poly(3-hexylpyrroles) oligomers at PM3.

\begin{tabular}{llllllll}
\hline $\begin{array}{l}\text { Number } \\
\text { units (n) }\end{array}$ & \multicolumn{7}{c}{ 3- Hexylpyrrole Derivatives } \\
\hline $\mathrm{n}=4$ & 3BHP & 3AHP & 3THP & 3CHP & 3HAHP & 3DTHP & 3DAHP \\
\hline Bond length & & & & & & & \\
$\mathrm{N}_{1}-\mathrm{C}_{1}$ & 1.397 & 1.395 & 1.395 & 1.395 & 1.395 & 1.395 & 1.397 \\
$\mathrm{~N}_{1}-\mathrm{C}_{2}$ & 1.408 & 1.406 & 1.406 & 1.406 & 1.407 & 1.406 & 1.409 \\
$\mathrm{C}_{2}-\mathrm{C}_{3}$ & 1.441 & 1.442 & 1.442 & 1.442 & 1.442 & 1.442 & 1.442 \\
$\mathrm{~N}_{2}-\mathrm{C}_{3}$ & 1.401 & 1.401 & 1.440 & 1.401 & 1.401 & 1.401 & 1.401 \\
$\mathrm{~N}_{2}-\mathrm{C}_{4}$ & 1.405 & 1.403 & 1.403 & 1.403 & 1.403 & 1.404 & 1.406 \\
$\mathrm{C}_{4}-\mathrm{C}_{5}$ & 1.439 & 1.440 & 1.440 & 1.440 & 1.440 & 1.440 & 1.439 \\
$\mathrm{~N}_{3}-\mathrm{C}_{5}$ & 1.398 & 1.398 & 1.398 & 1.398 & 1.398 & 1.399 & 1.398 \\
$\mathrm{~N}_{3}-\mathrm{C}_{6}$ & 1.401 & 1.401 & 1.401 & 1.402 & 1.402 & 1.403 & 1.401 \\
$\mathrm{C}_{6}-\mathrm{C}_{7}$ & 1.440 & 1.440 & 1.440 & 1.440 & 1.440 & 1.442 & 1.440 \\
$\mathrm{~N}_{4}-\mathrm{C}_{7}$ & 1.404 & 1.404 & 1.404 & 1.404 & 1.404 & 1.403 & 1.404 \\
$\mathrm{~N}_{4}-\mathrm{C}_{8}$ & 1.393 & 1.393 & 1.393 & 1.393 & 1.393 & 1.392 & 1.393 \\
$\mathrm{Bond}_{2}$ angle & & & & & & & \\
$\mathrm{C}_{1} \mathrm{~N}_{1} \mathrm{C}_{2}$ & 109.62 & 109.50 & 109.51 & 109.48 & 109.50 & 109.48 & 109.72 \\
$\mathrm{C}_{3} \mathrm{~N}_{2} \mathrm{C}_{4}$ & 109.55 & 109.26 & 109.34 & 109.29 & 109.40 & 109.25 & 109.60 \\
$\mathrm{C}_{5} \mathrm{~N}_{3} \mathrm{C}_{6}$ & 109.63 & 109.63 & 109.65 & 109.63 & 109.65 & 109.34 & 109.65 \\
$\mathrm{C}_{7} \mathrm{~N}_{4} \mathrm{C}_{8}$ & 109.83 & 109.84 & 109.84 & 109.84 & 109.85 & 109.55 & 109.84 \\
\hline
\end{tabular}

Table 3. Dihedral angles $\left({ }^{0} \mathrm{C}\right)$ of functionalized poly(3- hexylpyrroles) oligomers at PM3

\begin{tabular}{lllllll}
\hline \multirow{2}{*}{ Pyrrole } & $\mathrm{n}=2$ & \multicolumn{2}{c}{$\mathrm{n}=3$} & \multicolumn{3}{c}{$\mathrm{n}=4$} \\
\cline { 5 - 7 } & $\mathrm{N}_{1} \mathrm{C}_{2} \mathrm{C}_{3} \mathrm{~N}_{2}$ & $\mathrm{~N}_{1} \mathrm{C}_{2} \mathrm{C}_{3} \mathrm{~N}_{2}$ & $\mathrm{~N}_{1} \mathrm{C}_{4} \mathrm{C}_{5} \mathrm{~N}_{2}$ & $\mathrm{~N}_{1} \mathrm{C}_{2} \mathrm{C}_{3} \mathrm{~N}_{2}$ & $\mathrm{~N}_{2} \mathrm{C}_{4} \mathrm{C}_{5} \mathrm{~N}_{3}$ & $\mathrm{~N}_{3} \mathrm{C}_{6} \mathrm{C}_{7} \mathrm{~N}_{4}$ \\
\hline 3BHP & -161.81 & -160.20 & 145.20 & -18.80 & 145.55 & -60.27 \\
3AHP & -163.66 & -161.53 & 145.52 & -52.66 & 143.23 & -61.79 \\
3THP & -169.56 & -160.31 & 145.96 & -51.68 & 145.52 & -59.90 \\
3CHP & -120.41 & -161.06 & 144.74 & -53.89 & 141.69 & -60.34 \\
3HAHP & -97.04 & -160.46 & 142.28 & -51.39 & 142.18 & -61.21 \\
3DTHP & -154.83 & -128.02 & 141.38 & -54.06 & 142.54 & -24.72 \\
3DAHP & -125.12 & -160.86 & 145.56 & -19.54 & 144.76 & -61.52 \\
\hline
\end{tabular}

Figure 4 shows the evolution of the energy difference $(\Delta \mathrm{E})$ between the HOMO and the LUMO of 3AHP, 3BHP, 3CHP, 3DAHP, 3THP, 3HAHP and 3DTHP dimers as functions of torsion angles. As expected, the increment in interring torsion angles reduces the л-electrons delocalisation and consequently increases the energy gap $(\Delta \mathrm{E})$ between the $\mathrm{HOMO}$ and the LUMO ${ }^{22}$. The increment in $\triangle \mathrm{E}$ becomes faster at the larger torsion angles until it reaches optimum at $90^{\circ}$ (Figure 4). This is important for the effect of the torsion angles in different torsion range, which means that the effect is less at lower torsion angles than at higher ones. All curves of 3XHP are more or less overlap (except 3BHP), indicating that the electronic donating effect of the functional groups is not pronounced as 3BHP. The curve for 3BHP lies below, indicating stronger electronic donating effect of $\mathrm{Br}$ group. This is quite different from the semi empirical (PM3) results for hexylthiophenes (3XHT) analogues in which $\mathrm{N}, \mathrm{N}$-dimethylhexylthiophene dimer 
(3DAHT) has the stronger electronic donating effect ${ }^{20}$. This is an indication that the nature of heteroatom on the rings chain of the polymer affects the electronic donating effect of the functional group attached to the hexyl substituent of the polymer.

Finally, the results obtained in the present study showed that the inclusion of functional groups to alkyl side chain in pyrrole derivatives allow selective control of the molecular structure and energy band gaps that are sufficient to control macroscopic properties.

Table 4. HOMO-LUMO energy band difference (energy band gap (Eg)) in $\mathrm{eV}$ at PM3 level of semi empirical calculations

\begin{tabular}{llllllll}
\hline Pyrrole & 3BHP & 3AHP & 3THP & 3CHP & 3HAHP & 3DTHP & 3DAHP \\
\hline Monomer & 8.87 & 9.92 & 9.43 & 9.93 & 9.93 & 9.44 & 9.93 \\
Dimer & 8.03 & 8.35 & 8.36 & 8.96 & 9.50 & 8.26 & 8.85 \\
Trimer & 7.75 & 7.86 & 7.86 & 7.88 & 7.90 & 8.06 & 7.86 \\
Tetramer & 7.54 & 7.73 & 7.71 & 7.76 & 7.74 & 7.90 & 7.56 \\
H$^{*}$ & 6.51 & 6.70 & 6.93 & 6.74 & 6.73 & 7.14 & 6.53 \\
\hline
\end{tabular}

$\mathrm{H}^{*}$ is the energy band gap for the infinity polymers calculated considering a linear behavior $(\mathrm{Eg})$ with $1 / \mathrm{n}$ being number of monomeric units

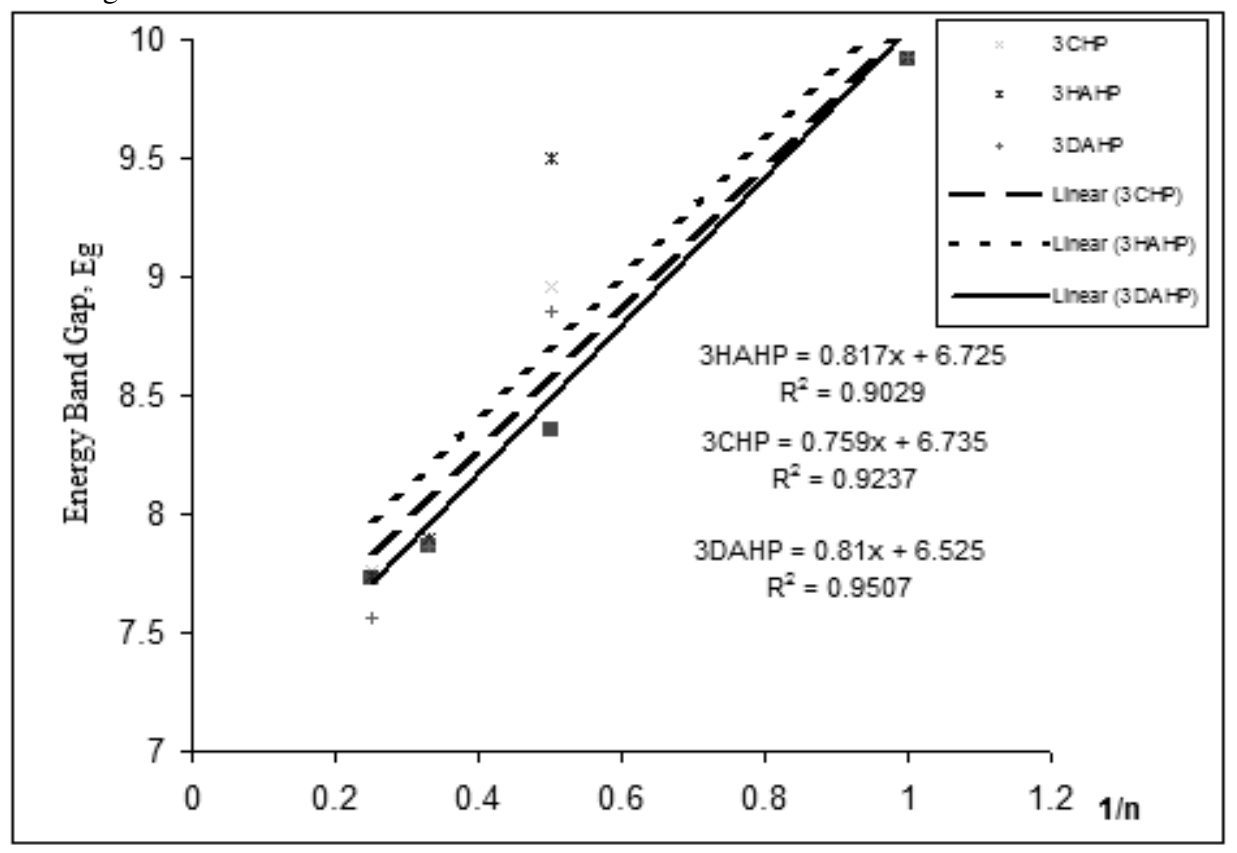

Figure 2. Correlation of energy band gap (Eg) and reciprocal of the number of pyrroles $(1 / \mathrm{n}), \mathrm{n}$ being the number of monomeric units.

\section{Torsion potential of dimers}

The torsion potential curves for 3BHP, 3AHP, 3THP, 3CHP, 3HAHP, 3DTHP and 3DAHP associate with the rotation of the dimers in different directions are displayed in Figure 4. Analysing Figure 4 shows that potential curves for 3XHP dimers are relatively flat (except $3 \mathrm{CHP}$ and $3 \mathrm{HAHP}$ ) between $0^{\circ}$.and $80^{\circ}$ (change in energy is $<1.0 \mathrm{Kcal} / \mathrm{mol}$ ), This segment 
would be largely twisted in their free states as shown in the dihedral angles of the most stable conformation in Table 3.

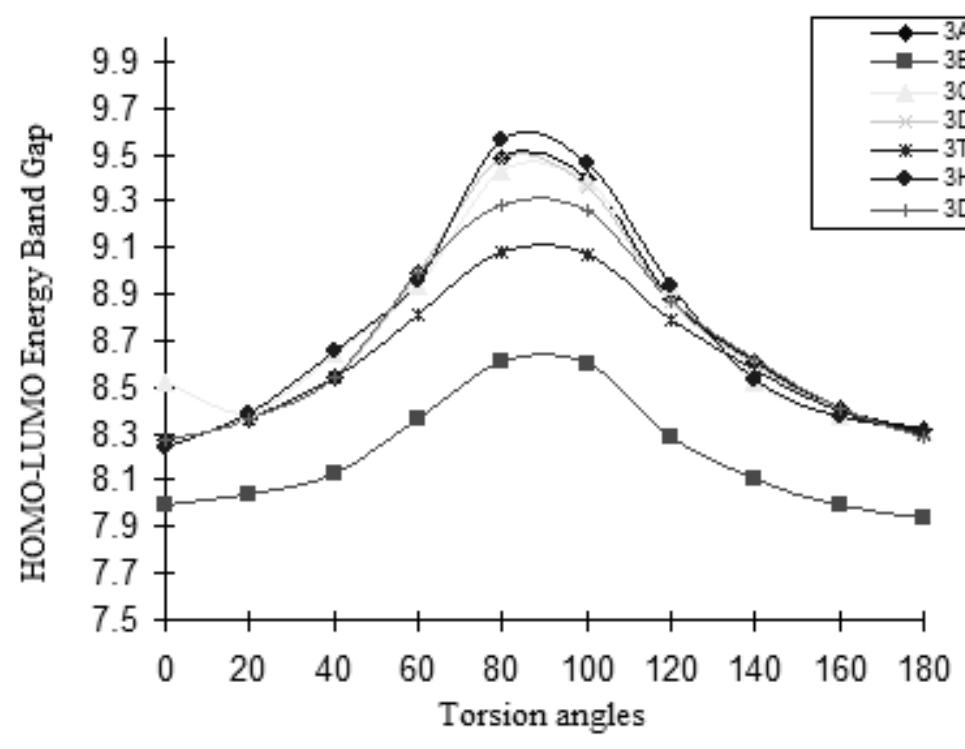

Figure 3. Evolution of the energy difference between the HOMO and the LUMO as a function of the torsion angle between rings

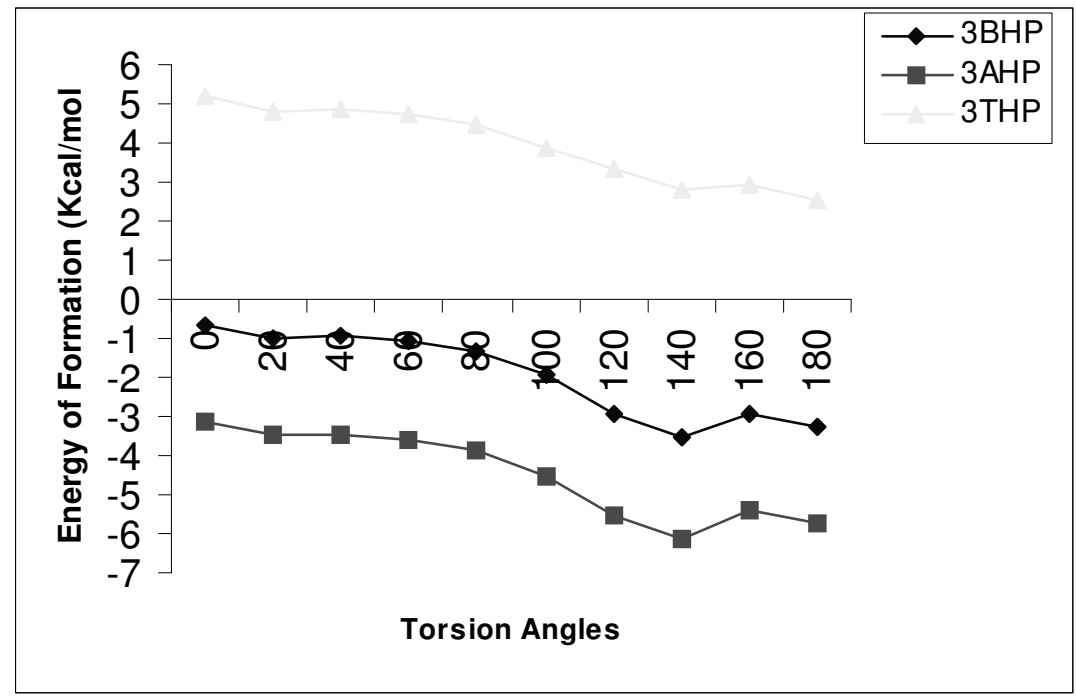

(a) 
(b)

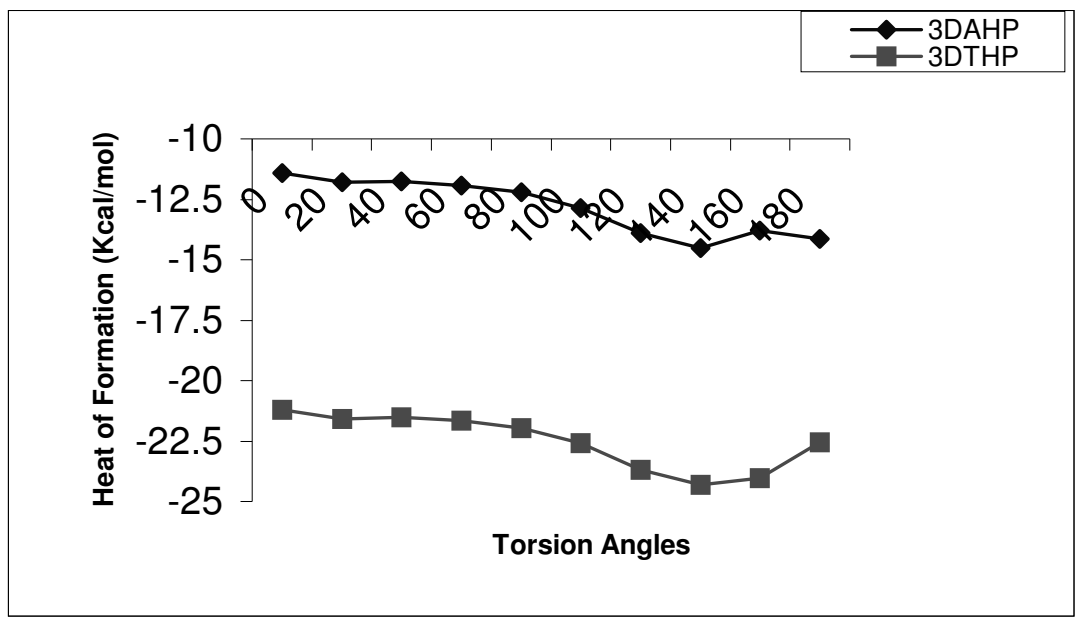

(c)
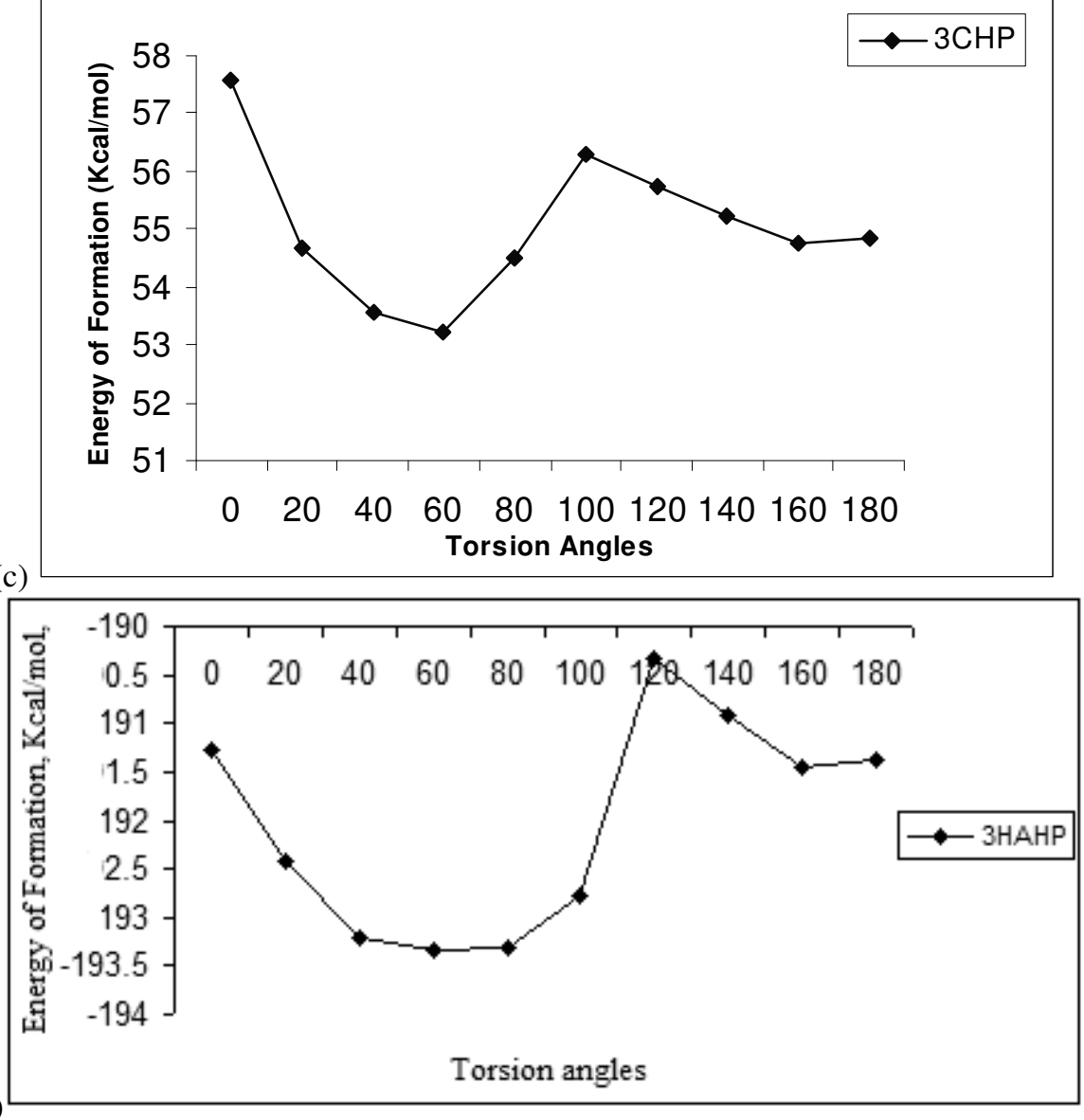

Figure 4. Torsion potential curves of the functionalized hexylpyrroles obtained with PM3 calculations 
The energy barrier height is compared to the equilibrium energy of 3XHP dimers in the free state. The energy barriers towards co-planar conformation are high for 3BHP, 3THP and 3DTHP and they are $4.01,5.17$ and $4.44 \mathrm{Kcal} / \mathrm{mol}$ for the $0^{\circ}$ conformation and $1.36,2.54$ and $3.11 \mathrm{Kca} / \mathrm{mol}$ towards $180^{\circ}$ conformation respectively. The energy barriers towards perpendicular conformation for 3BHP, 3THP and 3DTHP are $3.03,4.14$ and $3.38 \mathrm{Kcal} / \mathrm{mol}$ respectively.

In the case of 3AHP, 3DAHP, 3CHP and 3HAHP, the energy barriers towards $0^{\circ}$ conformation are $2.23,0.90,1.55$ and $0.04 \mathrm{Kcal} / \mathrm{mol}$ and that of towards $180^{\circ}$ conformation are $0.41,1.91,1.10$ and $0.06 \mathrm{Kcal} / \mathrm{mol}$ respectively. The energy barriers towards perpendicular conformation for 3AHP, 3DAHP, 3CHP and 3HAHP are 1.15, 0.27, 0,56 and $0.41 \mathrm{Kcal} / \mathrm{mol}$ respectively. This initially confirm that $3 \mathrm{AHP}, 3 \mathrm{DAHP}, 3 \mathrm{CHP}$ and 3HAHP would be very flexible in the polymers chains and probably adopt co-planar conformations where the polymers chains are close enough. The change of the torsion curves of 3CHP and $3 \mathrm{HAHP}$ are very similar with that from 3 -cyanohexylthiophene $(3 \mathrm{CHT}){ }^{20}$. However, the coplanar energy barrier for $3 \mathrm{HAHP}$ is largely reduced $(<0.1 \mathrm{Kcal} / \mathrm{mol})$ in the hexylpyrrole carrying the carboxylic group. From the potential curves, the number of carbon atoms of the hexyl group may not be the major factor that determines the co-facial packing distance, but also the functional group attached to the hexyl substituent.

\section{Conclusions}

The structure and energy band gap were calculated for series of 3XHP oligomers using semi empirical methodology based on PM3 approaches. The 3BHP has lowest energy band gap as calculated by PM3 method. The extrapolation of energy band gaps was predicted for the functionalized oligohexylpyrroles.

In general, our results show that the energy band gap does change with the functional group attached to hexyl substitutent and that the nature of the heteroatom in the rings chain affect the conjugation, and hence the molecular properties related to the electronic conductivity.

\section{References}

1. Kincal D, Kamer A, Child A D and Reynold J R, Synth. Met. 1998, 92, 53.

2. Kamp N.T, Flannagan G U, Kaisar A B, Trodabi H J, Chapman B, Paritridge A C and Buckley R G, Synth. Met. 1999,101, 434.

3. Jerome C, Labaye D, Bodert I and Jerome R, Synth. Met. 1999,101, 3.

4. Smela E, Micromech. Mocroeng. 1999, 9(1), 1.

5. Takamatsu T, and Taketani Y, Jpn. Kokai. Tokyo Koho JP11 121, 279 [99 121, 279].

6. Kojima Y, Kamikawa H and Takamatsu T, Jpn. Kokai. Tokyo Koho JP11 121. 280 [99 121280$]$.

7. Skotheim T A, Ed., Handbook of conducting polymer Vol I and II, Marcel Dekker, Newyork 1986.

8. Campbell T E, Hodgson A J and Wallace G G, Electronanalysis, 1999, 11(4), 213

9. Iroh J. O and Williams C, Synth. Met. 1999, 99,1.

10. Wallace G G, Spinks G and Teadale P R, Conductive electroactive polymers. Technomic, Newyork, 1997.

11. Tanaka K, Shichiri T, Toriumi M and Yamabe T, Synth. Met. 1989, 30, 271.

12. Sargn P. S, Toppare L and Yurtsever E, Polymer 1996, 37, 1151. 
13. Bredas J I, Street G B, Themans B and Andre J M, J. Chem. Phys. 1985, 83, 1323.

14. Orti E, Sanchez-Marin J and Tomas F, Theo Chem. Acta 1986, 69, 41.

15. Meyers F, Adamt C, Toussaint J M and Breder J I, Synth. Met. 1991, 41, 3559.

16. Yurtsever M and Yurtsever E, Tr. J. Chem. 1998, 22, 87-90.

17. Halgen T A, J Compt. Chem. 1996, 17, 490.

18. Kong J C A, White A I, Kryluv C D, Sharill R D, Adamon T R, Furlani M S Lec A M, Lee S R, Gwaltney T R, Adams C, Ochsenfeld A T B, Gidert G S, Krddziora V A, Rassollov D R, Maurice N, Nair Y, Shao N A, Bashey P E, Maslen J P, Domobroski H, Daschil W, Zhang P P, Korambath J, Baker E F C, Byrd T, Van V A, Oumi S, Hirata C P, Hsu N, Ishikawa T, Florion A, Warshet B G, Johnson P M W, Gui M, Head-Gordon and Pople J A, J. Comp. Chem. 2001, 21, 1532.

19. Spartan essential 2.0.1, Wavefunction, Irvine, 2005.

20. Odunola O. A and Semire B, e-polymers (in press), 2006.

21. Imamura A, Orimoto Y and Aoki Y, Theo. Chem. Acta.1999, 102, 180; Yurtsever E, Synth. Met. 1999,105, 179.

22. Jing-Fang P, Soo-Jinc and Wei H, Chem. Phys. Lett. 2002, 363, 18-24. 


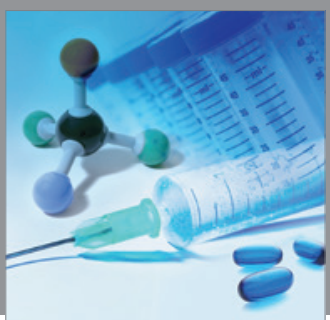

International Journal of

Medicinal Chemistry

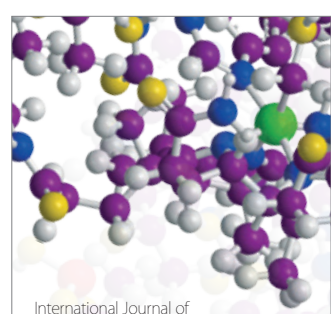

Carbohydrate Chemistry

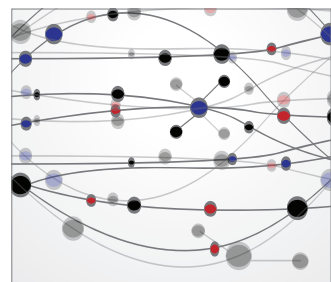

The Scientific World Journal
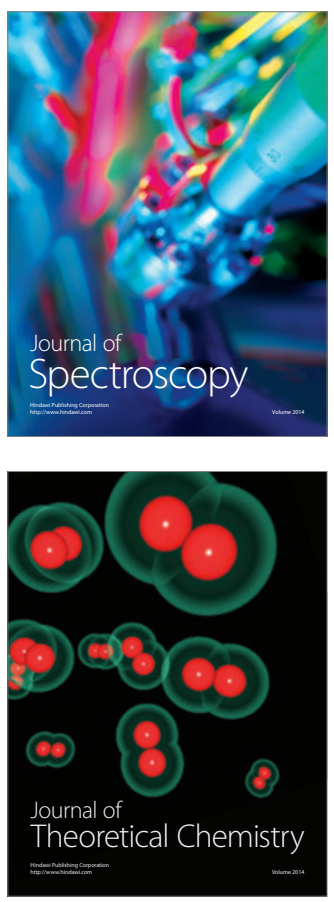
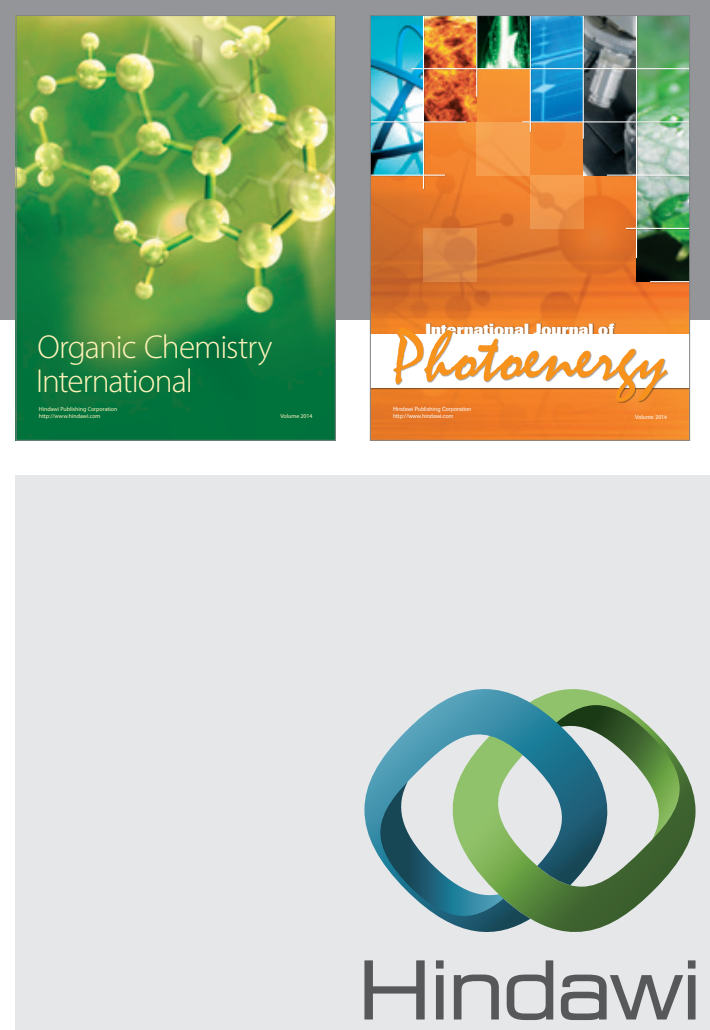

Submit your manuscripts at

http://www.hindawi.com
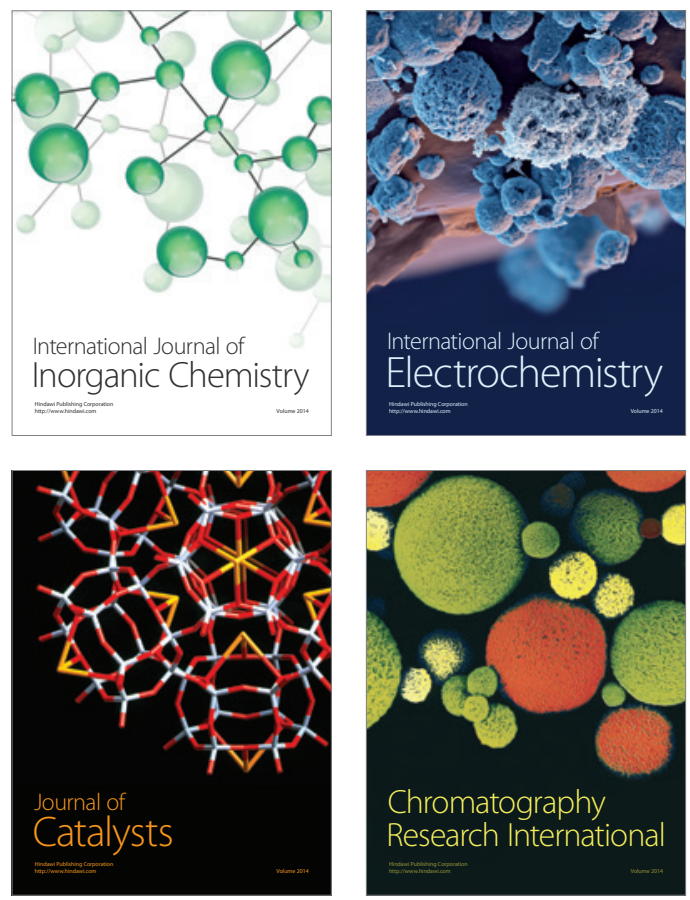
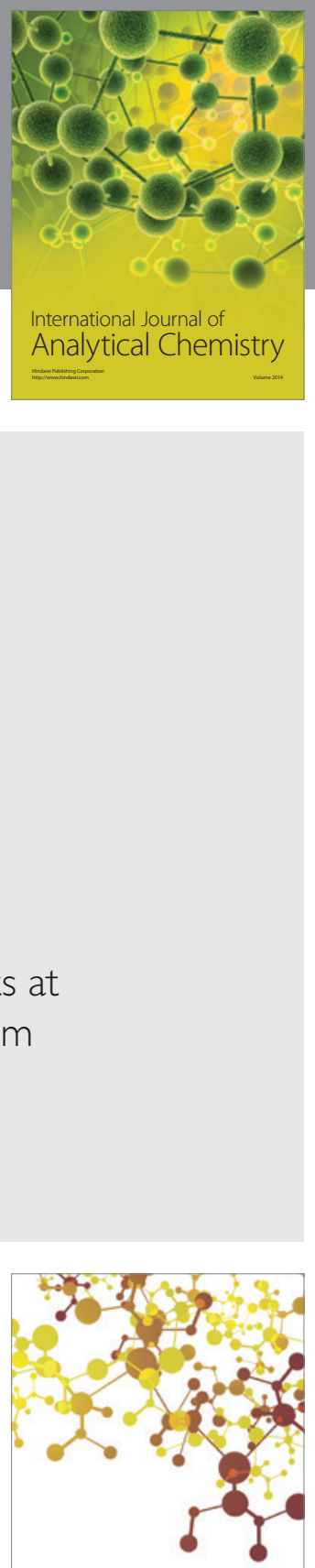

Journal of

Applied Chemistry
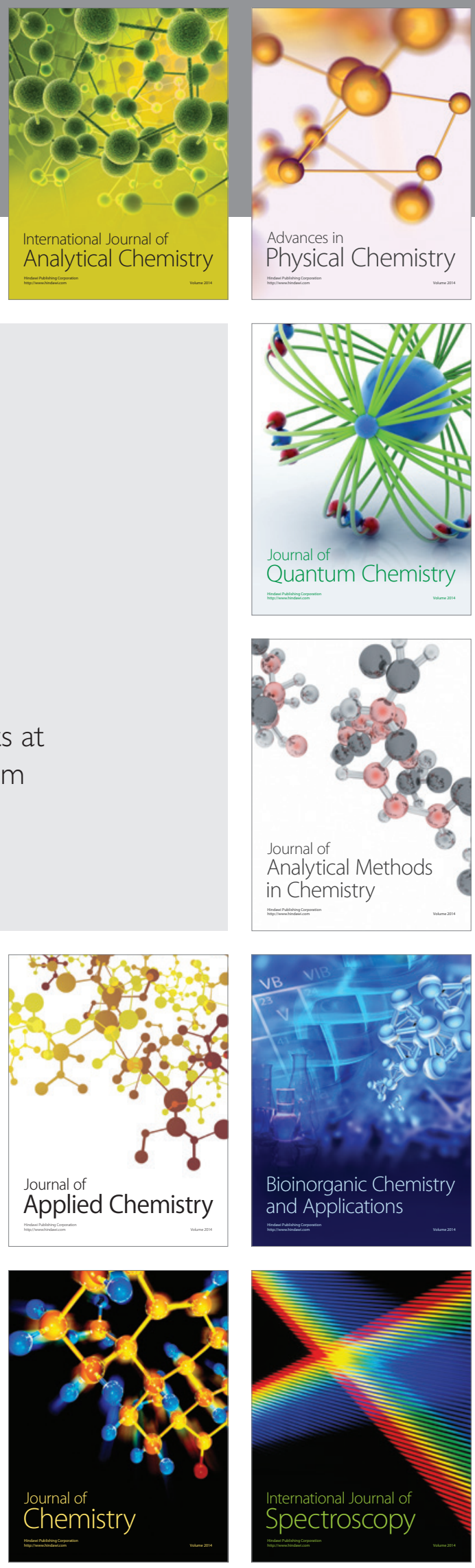